\title{
Effect of three single-nucleotide polymorphisms in CAPN1 gene on beef tenderness (Brief Report)
}

\author{
Einfluss von drei Einzelnucleotidpolymorphismen im CAPN1 Gen \\ auf die Zartheit von Rindfleisch (Brief Report)
}

\begin{abstract}
LILIANA A. SORIA' ${ }^{1}$, PABLO M. CORVA², ANDREA BRANDA SICA ${ }^{6}$, ALEJANDRO SCHOR LILIA M. MELUCCI ${ }^{2}$, EDGARDO L. VILLARREAL ${ }^{4}$, CARLOS A. MEZZADRA ${ }^{4}$, RODOLFO J. C. CANTET $^{5}$ and MARÍA C. MIQUEL ${ }^{1}$
\end{abstract}

\begin{abstract}
'Facultad de Ciencias Veterinarias, Universidad de Buenos Aires, Argentina, ${ }^{2}$ Facultad de Ciencias Agrarias, Universidad Nacional de Mar del Plata, Balcarce, Argentina, ${ }^{3}$ Facultad de Agronomía, Universidad de Buenos Aires, Argentina, ${ }^{4}$ Instituto Nacional de Tecnología Agropecuaria, Balcarce, Argentina, ${ }^{5}$ Facultad de Agronomía, Universidad de Buenos Aires, Argentina y Consejo Nacional de Investigaciones Científicas y Técnicas (CONICET), Argentina, "Unidad de Biotecnología, Estación Experimental Las Brujas »Wilson Ferreira Aldunate", INIA, Uruguay
\end{abstract}

\section{Background}

Meat tenderness is an important trait in beef cattle production, as consumers consider tenderness the most important attribute of beef palatability. There is ample evidence that post mortem proteolysis of myofibrillar proteins is responsible for the decline in shear force during storage. The bovine micromolar calcium-activated neutral protease (CAPN1) gene encodes the large subunit of $\mu$-calpain, which is thought to be one of the most important enzymes involved in post mortem tenderization (KOOHMARAIE 1996). Three single-nucleotide polymorphisms (SNPs) on the CAPN1 gene (316, 530 and 4751 markers) have been associated with tenderness in different cattle breeds (PAGE et al. 2002, PAGE et al. 2004, WHITE et al. 2005). A more recent study confirmed that markers 316 and 4751 had an effect on beef tenderness (VAN EENENNAAM et al. 2007). The objective of this research was to determine the existence of polymorphisms and to assess the effect of the reported SNP in the bovine CAPN1 gene on tenderness from a sample of Angus and Brangus steers fattened on pasture.

\section{Procedure}

Sixty Brangus and 21 Angus steers were used in the study. The Brangus steers were chosen at random from three different commercial herds ( $n=20$ each), which are representative of the breed located throughout Argentina. In all herds animals were purebreds, i.e. there were the progeny of either Brangus bull and cows, or Angus bulls and cows. Individual sire identifications were not available due to the multiple-sire mating system practiced in these herds. All Angus animals were produced at INTA Balcarce Experiment Station from cows belonging to a closed experimental herd. Animals were sorted into slaughter groups, classified by breed and herd origin. All steers from each group were slaughtered when at least $50 \%$ of them reached $6 \mathrm{~mm}$ of back fat thickness. Beef tenderness was estimated indirectly as Warner-Bratzler shear force (WBSF) 
measured on samples taken from the longissimus lumborum muscle at 1, 7 and 14 days post mortem (CORVA et al. 2007). After slaughter, and following a 24-hour cooling period at $1-5^{\circ} \mathrm{C}$, the block of steaks corresponding to the 11,12 and 13 th ribs was removed from each left half carcass, deboned and divided into three pieces that were vacuum-packed and randomly assigned to three maturation treatments at $1-5^{\circ} \mathrm{C}(1,7$ and 14 days). After ageing, meat samples were frozen and kept at $-20^{\circ} \mathrm{C}$ until they were thawed. DNA was isolated from blood by phenol/chloroform standard protocol. PCR-RFLP methods for markers 316 and 530 were carried out according CORVA et al. (2007). A 205 bp DNA fragment of marker 4751 was amplified with the following primers:

forward - GAA GGG CTT GGG TTG GGA TGT CGG CAG AG and

reverse - AGG CTG GGA GGG GTG TTC TCT GAG TGC CA,

and digested with the Bsall restriction enzyme. The effects of the three markers on WBSF were tested simultaneously by fitting a mixed model using PROC MIXED of SAS (1998). Fixed effects were treatment (ageing at 1, 7 and 14 days), slaughter group , treatment $\times$ slaughter group interaction, main effects of markers 316, 530, 4751, marker $316 \times$ treatment, marker $530 \times$ treatment, and marker $4751 \times$ treatment, and animal was considered random. Low frequencies in some of the marker genotypes, led to a lack of observations for different combinations of genetic markers, which prevented including the interactions among markers in the model. Meat samples from the same animal taken at different ageing times were considered repeated measures. The choice of covariance structure was tested with the Bayesian Information Criterion (BIC), and the variance components option in PROC MIXED was used for the analysis. Haplotyping was performed using the software PHASE (STEPHENS et al. 2001). Most likely haplotypes were included in the analysis if assigned with probabilities of 0.98 or more. Haplotypes were analyzed with a model that included fixed effects of treatment, slaughter group and treatment $\times$ slaughter group interaction and random effects of animal. Haplotype effects were fitted as a fixed regression in the number of haplotypes (i.e. $0,1,2$ ). Tests of hypothesis were performed in a stepwise fashion (see for example CORDELL and CLAYTON 2002).

\section{Results}

A large proportion of animals were GG homozygous at markers 316 and 530. Only one homozygous AA at marker 530 was found in the entire sample, and was excluded from all statistical analyses. Genotype CT at marker 4751 was the most frequent one. Only 4 haplotypes (CGC, GGC, GGT and GAT) were found among the eight possible. Tests of fixed effects showed that only treatment, treatment $\times$ slaughter group and marker 316 significantly $(P<0.05)$ affected WSBF. Marker 316 showed a significant effect on WBSF at 7 days $(P<0.05)$. At this ageing period, the difference between homozygotes CC and GG was $1.49 \pm 0.69 \mathrm{~kg}$. The heterozygous genotype showed an intermediate value. No significant differences were found between genotypes CC and CG, probably due to the low number of CC animals found in this study. At 7 days post-slaughter the shear force value decreased more in CC (31\%) than in GG (10\%). These results suggest that maturing periods longer than 7 days will not improve meat tenderness of steers carrying CC and CG genotypes at marker 316. For those carrying the GG genotype instead, 14 days were needed to reach 
tenderness values similar to those obtained at 7 days from animals with genotype CG. The absence of the AA genotype at marker 530 in these data may have resulted in the lack of difference among genotypes. If differences among marker 4751 genotypes are small, the number of animals sampled in the current study may not have been enough to detect them. All in all, the least squares means for marker 4751 do not indicate a clear trend for the effect of the SNP on tenderness. Table 1 shows the results of the analyses performed on each haplotype. The individual tests indicate that the effect of CGC was statistically significant, and GGC almost reached significance. The haplotype CGC gathered three favorable alleles for tenderness. When the model included the effects of both markers, only CGC was significant. No significant effects on tenderness were found for all other haplotypes. This result agrees with the analysis of genotypes in that a statistically significant effect $(P<0.05)$ was found for marker 316 on tenderness. Thus, the only marker having an effect on tenderness was 316 , since the haplotype carrying CGC was the only one that displayed a significant effect. In the latter analysis, the increase in the number of $C$ alleles from 316 was significant, whereas increasing the number of "favorable" alleles of either 530 or 4751 showed no significant effects. The effects estimated by the analyses of the haplotypes GGC and GGT do not show a clear trend for the effect of 4751 , and this result agrees with the one obtained from the genotypic analysis. Of the three markers analyzed in this study, 316 was the only informative marker for tenderness at 7 days post mortem. There was little variation at 530 in the current experiment, whereas 4751 displayed no clear effect on tenderness.

\section{Acknowledgements}

Funding for this research was provided by grants of Agencia Nacional de Promoción Científica y Tecnológica (BID 1728 OC/AR PICTR 00177). Animals were provided by INTA Balcarce and Asociación Argentina de Brangus. Data analyses were possible from a grant of CONICET (PIP 5338).

Table 1

Tests of hypotheses for the haplotype effects

Tests von Hypothesen für die Haplotyp-Effekte

\begin{tabular}{lrrrrr}
\hline Marker 316/530/4751 haplotype & 0 & \multicolumn{1}{c}{$N$} & 2 & $P$-value & Estimated effect, kg \\
\hline CGC & 132 & 96 & 12 & 0.0044 & $-0.672 \pm 0.23$ \\
GGC & 90 & 114 & 36 & 0.0562 & $0.407 \pm 0.21$ \\
GGT & 114 & 108 & 18 & 0.7938 & $0.070 \pm 0.27$ \\
GAT & 210 & 30 & 0 & 0.4331 & $0.375 \pm 0.47$ \\
Tests for haplotype effects in a model including both CGC and GGC & & \\
CGC & 132 & 96 & 12 & 0.0350 & $-0.618 \pm 0.29$ \\
GGC & 90 & 114 & 36 & 0.7589 & $0.078 \pm 0.26$ \\
\hline
\end{tabular}

\section{References}

Cordell HJ, Clayton DG (2002) A unified stepwise regression procedure for evaluating the relative effects of polymorphisms within a gene using case/control or family data: application to HLA in type 1 diabetes. Am J Hum Gen 70, 124-41 
Corva PM, Soria L, Villarreal EL, Schor A, Perez Cenci M, Motter M, Mezzadra C, Melucci LM, Paván E, Depetris G, Miquel MC, Santini FJ, Grigera Naón JJ (2007) Association of polymorphisms on the CAPN1 and CAST genes with meat tenderness in beef cattle of Argentina. Gen Mol Biol 30, 1064-9

Koohmaraie M (1996) Biochemical factors regulating the toughening and tenderization processes of meat. Meat Sci 43, S193

Page BT, Casas E, Heaton MP, Cullen NG, Hyndman DL, Morris CA, Crawford AM, Wheeler TL, Koohmaraie M, Keele JW, Smith TPL (2002) Evaluation of single-nucleotide polymorphisms in CAPN1 for association with meat tenderness en cattle. J Anim Sci 80, 3077-85

Page BT, Casas E, Quaas RL, Thallman RM, Wheeler TL, Shackelford SD, Koohmaraie M, White SN, Bennett GL, Keele JW, Dikeman ME, Smith TP (2004) Association of markers in the bovine CAPN1 gene with meat tenderness in large crossbred populations that sample influential industry sires. J Anim Sci 82, 3474-81

SAS Institute Inc (1998) SAS/STAT User's guide, Version 6. SAS Inst Inc, Cary, NC

Stephens M, Smith SJ, DONNELLY P (2001) A new statistical method for haplotype reconstruction from population data. Am J Hum Gen 68, 978-89

Van Eenennaam AL, Li J, Thallman RM, Quaas RL, Dikeman ME, Gill CA, Franke DE, Thomas MG (2007) Validation of commercial DNA test for quantitative beef quality traits. J Anim Sci 85, 891-900

White SN, Casas E, Wheeler TL, Shackelford SD, Koohmaraie M, Riley DG, Chase CC Jr, Johnson DD, Keele JW, Smith TPL (2005) A new single nucleotide polymorphism in CAPN1 extends the current tenderness marker test to include cattle of Bos indicus, Bos taurus, and crossbred descent. J Anim Sci 83, 2001-8

Received 24 April 2008, accepted 18 April 2009.

Corresponding author:

LILIANA A. SORIA

email: Isoria@fvet.uba.ar

Área de Genética, Facultad de Ciencias Veterinarias, Universidad de Buenos Aires, Chorroarín 280, C1427CWO Buenos Aires, Argentina 